\title{
From Sex Objects to Heroines-A Tough Road for Female Characters in Video Games*
}

\author{
Adam Flamma \\ University of Wroclaw, Wroclaw, Poland
}

\begin{abstract}
Female character in video games is the one of the most controversial topic in game studies and nowadays women's anthropology. From the beginning of role in games' plot to sexualized graphical representation, woman in virtual world were (and sometimes still are) a point of discussion about characters sexualisation and role of female sex in virtual industry. The main aim of this paper is to present analysis of female representation in video games and how in last 30 years it has changed. In other words, how female characters were ennobled from sex object to main protagonist status. In presented research, there were used mostly the examples of popular video games with extended plot and world which can be explored by protagonists. Video game historiography, textual analysis (which helped to treat video game character as a protagonist), and thematic analysis of video games were used as a main research method. The main conclusion of this paper is that female characters can overcome all gender or sexual stereotypes and even eventually became an icon of popular culture.
\end{abstract}

Keywords: video games, female characters, women in video games, sex object, Lara Croft

\section{Introduction}

Video games have constituted a basis for professional and scientific investigative analysis for some time now, becoming a subject of interest for engineers and all sorts of scientists as well as humanist scholars. The later have especially transformed the perception of video games and began to regard them as an alternative form of narrative. Espen Aarseth ${ }^{1}$ and Carlos Alberto Scolari ${ }^{2}$ have written widely on this subject. However even they, describing the occurrence of trans-media storytelling or the phenomenon of cyber text, placed more emphasis on the story, and the way transposition to another medium influences it and its dissemination, than its main characters. The complexity of main characters in video games - their psychology, text analysis, or the method (comparable to a literary one) of interpreting and defining a main character as an entity — only recently has constituted a subject for scientific inquiry. The female character has been placed in an interesting manner in this subject matter. In video games, she has undergone a true evolution. Although today their presence in video games

\footnotetext{
* Adam Flamma is a beneficiary of the scholarship programme „Rozwój potencjału i oferty edukacyjnej Uniwersytetu Wrocławskiego szansą zwiększenia konkurencyjności uczelni” co-financed by European Social Founds.

Adam Flamma, Ph.D. candidate, master, Faculty of Philology, University of Wroclaw.

1 Cybertext: Perspectives on Ergodic Literature (1997).

2 Transmedia Storytelling: Implicit Consumers, Narrative Worlds, and Branding in Contemporary Media Production (2009). International Journal of Communication (nr. 3, 586-606).
} 
is no longer anything unusual, in fact lack thereof is startling and may prompt players' outrage (like in Battlefield 4 game), it is important to note that it has not always been as such.

The matter of the origins of female characters' presence in video games is closely related to the idea of the main character/hero itself. Initial video games, such as even the now "legendary" Pong (Atari Inc., Allan Alcorn, 1972) or other inspired by it, did not actually tackle the topic of a main character. This role was fulfilled by the player himself, who through elements such as a joystick carried out different actions, which in effect altered occurrences in the game that were visible on a monitor. This does not mean that a hero as a feature figure (or simply an element of the plot) did not exist. Certainly, the appearance of a hero surfaced, although not in games with graphics. Those, at least in the onset, presented relatively simple sport simulations. The main character appeared in textual games, however, it was almost always a male. Consequently, earliest female characters had to emerge in textual games. That was dictated basically due to a simple technological restriction-arcade video games or other early mechanical and electronic console video games were not graphically (technologically) able to depict female characters or the characters' gender in general ${ }^{3}$.

\section{First Steps}

When it comes to the evolution of video games, initial arrival of female characters of significant role in the world of games, was fairly symptomatic. Namely, it was linked to the emerging, and rapidly flourishing development of a multimedia branch of industry, known as erotic video games. It was in these erotic and later pornographic video games, that female characters were originally being presented. The earliest of these games (and without a doubt a critical one), was Softporn Adventures Adventures (On-line Systems, Chuck Benton, 1981) intended for Apple II. There, the player became a waiter, who was to serve attractive women and attend to their needs and desires, in hopes of being able to spend pleasurable moments with one of them (most likely physical contact was part of the goal, yet it was not actually shown; merely implied, leaving it to the player's assumption). This particular game turned out to be incredibly popular and it initiated a large trend of erotic themed video games. In the years 1982-1984, around the time of Benton's video game premier, Bachelor Party, Gigallo, and Jungle Fever or X-man also appeared. All the more, a studio named Playaround, specializing solely in erotic themed video games, was created for the Atari 2,600 platform. As a result, thanks to Playaround and the aforementioned games, women became synonymous with eroticism and sex in video games. Despite the fact that the story-lines were presented in a humorous manner, it is impossible to deny that the sexual implications were obvious. Still, unlike On-Line Systems productions, in these games we could see first visual representations of women; usually naked with clearly emphasized breasts and buttocks. This tendency spread with the arrival of the Commodore 64 computer, and in turn trickled into first strip poker simulators. In games such as Animated Strip Poker or Artwork Strip Poker, the player's opponent was a woman, who after a loss, unveiled a following element of her body. Usually however, the object of these games was to rid the opponent (the female character) of her blouse and bra. Rarely was there a possibility of revealing any other part of the woman's body. Subsequently the woman became a sexual object and a quest for the player. Despite increasing interest, her image, though more and more frequent, was very typical and oriented around erotic motives. Similar was the case with the representation

\footnotetext{
${ }^{3}$ In the case of textual games, (though it was not the rule) images of heroes usually appeared on the front covers of games.
} 
of women in video games created in Japan. There, fairly quickly, women became sexual objects in games. A best example of this is Night life, a game from the KOEI studio, where despite deficient graphics (woman is presented only as a white shape on black background), a woman's presence is limited to physical erotic contact with a man steered by the player. It is worth mentioning that the female characters were sometimes victims of humiliation because of their sexuality. An example of this is a onetime very popular game Sex games (Landisoft, 1985), in which a woman, depicted visually in a very humorous and sometimes even embarrassing way (ugly face, disproportional figure, dopey facial expressions, etc.) becomes an element of a sexual puzzle, in which the objective is to arrange a line of men with erections, with women, in any desired, domino-like fashion. Additionally, what sets Sex games apart from Night life, there are specific sexual positions that can be played out, incorporating oral and anal sex?

\section{The Beginnings of Emancipation}

A change in the context in which women were presented in video games, produced by Amiga, a platform that delivered games such as Fascination or more specifically a Leisure Suit Larry series (which later became compatible with PC and eventually converted to that format) where the female character underwent a significant improvement. She continued to be associated with eroticism, however she gained considerable autonomy, acquired more function within the game and her character expanded as a whole. As much as the afore-named Fascination showed women as sexual instigators or victims, the game series about Larry Laffer's adventures (especially in later installments) significantly broadened their portrayal. It is noteworthy that although both games are highly eroticized, the scope and influence of Leisure Suit Larry reached a significantly greater group of recipients, than those of previously mentioned games; becoming a classic in its own right. This $\mathrm{Al}$ Lowe series had its premier in 1987 (Leisure Suit Larry in the Land of the Lounge Lizards by Sierra On-Line) whereas the last part (Leisure Suit Larry: Love for Sail! By Sierra On-Line) was launched in $1996{ }^{4}$.

The main character of the series is Larry Laffer, a 40 year old man, whose biggest passion and meaning in life is seducing women and finding the love of his life. Because he is not too handsome, he must rely on his personal charm. This often creates many amusing situations. In his adventures, women were initially depicted in a very stereotypical and highly sexualized manner: They wear skimpy and tight clothing, often partially naked. They are usually full of sex appeal, pretty, with large breasts and nice figures. However, aside from being an "enhancement", they are quite commonly just providers of a quest for the main male character. His aim is to fulfill each woman's request and desire, in order to finally persuade them into physical contact with him. This is not that simple, in view of the fact that Larry notoriously falls victim to jokes and tricks from the women, who often treat him like a naïve loser. This way they create the main character's fate and determine his and often their further actions. Additionally, they sometimes accompany him in his adventures. Namely, to assist him in his assignments or explore further places with him; places where the storyline unveils. Therefore, their status has undergone serious changes and although they were still peripheral characters, looking at it from a "backdrop" point of view, or frankly speaking, from a strictly sexual standpoint, they became supporting characters, heroines, or even companions or partners. Still, they were mostly sources of a challenge (which we see in Softporn

\footnotetext{
${ }^{4}$ The series also contains a 2004 Leisure Suit Larry: Magna Cum Lade (High Voltage Software, Sierra Entertainment Inc., yet not as popular with fans. Perhaps because Al Lowe was no longer the producer.
} 
Adventures) or their mere presence was related to some sort of erotic themes. As characters, they did encompass certain specific elements, such as interests, particular sayings, or fears (such as fear of spiders).

It is significant to bring up an example from the last installment of the game Larry: Love for Sail! in which all the female characters shown are intelligent, pretty, and sexy as well as having an extended and rich personal history, on which they expand. They also hold higher degrees and have experience linked to a specific trade which they learned, as well as certain character traits. An amplification of this mechanism is no doubt the most significant (and rightfully so) heroine in the game, Captain Thygh, Larry's love interest. Not only do we encounter her quite often in the game (incidentally, we tend to see female characters more frequently throughout the length of the game), we also learn of her rich personal history as well as of her ability to do more than just manipulate the main character. Above all, she plays an important role — she is the captain of a ship, displaying an enormous amount of responsibility. This is an entirely new concept, since previously women were not shown in professions of great responsibility, requiring certain predispositions, experience, and knowledge. Moreover, they were not portrayed as having a profession or trade of any kind.

\section{The Thrill Seeker}

In the history of the video game industry, without a doubt, the most significant influence on the perception of women was the character of Lara Croft, a heroine of the Tomb Raider series. Today, quite the legend, often labeled an icon of pop culture and a symbol of emancipation for women in multimedia, Croft debuted on the monitors of video games in 1996. These were times where players mostly did not have the capacity to control and navigate female characters, and video game plots were rather masculine. Miraculously, a British developers studio Core Design, achieved a true turnaround in this matter, creating a video game heroine who was not only a beautiful lady, but an archeologist turned thrill seeker, ready for any adventure. Beautiful, curvaceous, initially having large breasts, dressed in tight shorts and blouse - that was the introductory image of Lara Croft. Additionally, she was a skilled weapons handler, using a shotgun, an Uzi rifle, or two beretta pistols simultaneously, all of which she expertly used in battle against wild animals (bats, bears, dinosaurs) or evil humans. Thus, the Tomb Raider heroine, though initially comparable to Indiana Jones, became an independent and an unique character that encompassed all the traits required to become an ideal protagonist (Kennedy, 2002) of the entire series: She was brave, in great physical shape, intelligent, inquisitive, challenged men (usually winning), and had a sense of humor and a pretty face, which incidentally, allowed her creators to use her image in marketing campaigns. It is this last matter that at some point took control over Lara's initial identity which we can observe in game. Within a short period of time, Croft was visible in all sorts of commercials everywhere. Furthermore, these commercials used her physical attributes - depicting her nude or in sexually insinuating situations. At the same time, her image, nonetheless, is painted as that of someone who is strongly connected with her own sexuality (Anderson \& Levene, 2012). Paradoxically, it is she, who according to many researchers (Kennedy, 2002; Schleiner 2001), epitomizes the emancipation of women in video games. In certain ways, changes in her appearance support such notion. Certainly, it should be noted that despite an extremely quick technological progress, Lara Croft's image did not significantly encounter a noticeable alteration until Tomb Raider Legend (Crystal Dynamics, Eidos Interactive, 2006). It is in this particular installment that her physical features and perhaps her level of sexuality are revised, since her breasts are much smaller than in the first portions 
of the series. Moreover, her outfit seems even more skimpier, though her overall figure is more realistic. In some ways, this amounts to two realizations regarding change: an emancipation in relation to a man's world (visible from the very beginning); and a gradual (but consistent) freeing from the stereotype of a sex symbol. A pinnacle point, especially in this last mentioned matter, turns out to be the last series installment, Tomb Raider (Crystal Dynamics, Square Enix, 2013), in which the protagonist is a young lady (she is barely eighteen years old) with a proportional figure. Her body is not exaggerated by disproportions between her large breasts and slim waistline, as was the case in the initial games. Again, a key to her sexuality is the size of her breasts, which this time is small. In turn, when it comes to her attire, throughout most of the game Lara wears long, tight-fitting pants, which replace her shorts.

Nonetheless, Lara Croft does not only represent the physicality or sexuality of female characters in video games. She is also, if not above all, a fully-fledged heroine with an extremely abundant and heart-rending personal history, which the player discovers over time while playing through all the series. We find that her personal history consists of elements such as her background (one of nobility, which is a first for female characters in video games), personal traumas (due to the loss of her parents), conflicts, ambitions and many talents (such as her fluency in many languages), all of which are supported by many anecdotes. Of course, despite these many elements, generally speaking, Lara Croft still usually functions as a sex symbol (although, paradoxically, she is less connected to that image than female characters in earlier video games), though it is more of an effect of an installed and established stereotype, than the actual case.

Regardless, this heroine of Tomb Raider became an inspiration for placing women as main characters in video games. Unlike men, Lara Croft showed functionality of a female as a protagonist: her personal charm and undoubtedly greater plot and character expansions. She also revealed an interesting mechanism-a woman-heroine actually became interesting to men (mainly from an aesthetic standpoint) as well as women, who could now identify with her. As a result, subsequent distinctive heroines emerged on the video game market fairly quickly. This tendency blossomed mainly in the world of adventure type video games and is the case to this day. Best examples of this are games such as Gray Matter (Wizarbox, dtp AG/Anaconda, 2010), Remember me (Dontnod \& Capcom, 2013), the Secret Files series or bona fide classics along the lines of The Longest Journey (Funcom, 1999) and Dreamfall: The Longest Journey (Funcom, Aspyr Media, 2006). In this paper, the rearmost two will be examined, owing to the fact that their significance on video game history as a whole, as well as their influence on other games of this genre, is important enough, that these two particular games established the norms for adventure type video games. It is these two games that most other ones are compared to.

The main character in both The Longest Journey (Funcom, 1999) and Dreamfall: The Longest Journey (Funcom, Aspyr Media, 2006) is April Ryan, an Arts Academy student, who lives in an apartment-house with other students. Humble, quiet and initially shy — such is the impression the player gets of her in the beginning. From the time she is introduced, in terms of her physical appearance, certainly she is not presented strictly as a sexual being. Long pants, traditional round-neck t-shit—which is a typical outfit we see Ryan in. During the course of the game we have an opportunity to discover her personal history, completely purged of any erotic context (although we see a theme of her reserved feelings toward one of her male friends). Instead, we see an array of her problems with self-acceptance and similar issues (no doubt a cause of which was her childhood abuse 
by her father). Additionally, April is depicted as a person who is constantly short on money, is neither athletic nor physically strong, and her innate timidness leads to her numerous problems with assimilating into society (such as with other students), acclimating to new places and meeting new people. What is interesting is that in the second installment of the game-Dreamfall: The Longest Journey-Ryan seems to transform into a completely different person. There, she is a critical part of a particular social group (she leads those fighting for freedom of an alternative world called Arcadia), she is physically stronger and handles weapons such as a sword and a cane. Just the same, this change in her persona appears to have an effect on her psyche, which is manifested by her withdrawal from any and all female attributes, such as feelings for any man, or minding her physical appearance. In Dreamfall: The Longest Journey, April is usually shown wearing a broad, dark coat, holding a cane in her hand. From the onset, her main objective in the game is completing her given task, which is freeing the people of Arcadia. Incidentally, there is no sexualization of her character to be mentioned, simply because no aspects of such are present to even qualify for commentary (Hatton \& Trauter, 2011). Even so, she is a character, who in light of her personal history, is regarded as intriguing, although this notion is not linked to any physical characteristics or attributes related to sexuality (Sharkey, 2008; Mcconnell, 2011).

Another incredibly interesting example of a female character in video games is a protagonist in Dreamfall: The Longest Journey, Zoe Castillo. It can be said that in order to create her image, certain character traits of both Lara Croft and April Ryan were compiled. Specifically, she is pretty, even sexy, wearing crop tops (exposing her stomach and shoulders), unveiling a large cleavage ${ }^{5}$. Aside from that, she habitually wears make-up, which emphasizes her full lips and big eyes. She herself admits that she cares about her appearance. Zoe often flits with boys. She is very open-minded and at times very straightforward in terms of interpersonal relations. She does not suffer from insecurities and did not have a failed childhood, as did April Ryan. Nonetheless, one of her most important personal traumas becomes a justification for her actions and her biggest motivation: the disappearance of her boyfriend, whom she still is in love with. In order to find him, she carries out all sorts of dangerous assignments that bring out in her, characteristics more associated with Ryan. These are: determination, imagination and ambition, which often enable her to triumph over physically stronger opponents (mainly men). Like Ryan, Castillo is not presented in any erotic situations, although she continues to have strong feelings for one person and sometimes carries on conversations about boys (with her girlfriends).

The examples mentioned in this article, as well as other ones of the adventure-type video games, are proof of continuing changes in the way women are depicted in video games. They cease to be displayed as simply sexual objects, and grow to equal their male counterparts. The situation is similar with regard to the computer Role-Playing video games (cRPG), yet it should be noted that in the classic versions of these types of games (for example the Baldur's Gate series or Icewind Dale) eroticism is highly marginalized or almost nonexistent, because it does not have any significant impact on the gender of the characters. Likewise, the gender of the character (who is navigated by the player) alone, did not have any meaningful affect on the plot $^{6}$. It did have an effect in classic games, however, in newer ones such as The Elder Scrolls V: Skyrim (Bethesda Game Studios,

\footnotetext{
${ }^{5}$ Castillo's attire is very significant from the very beginning, because we see her wearing pajamas in the initial scenes, which was not the case with Ryan at all.

${ }^{6}$ Surely, an exception is Baldur's Gate II: Throne of Bhaal, where a romantic theme unravels. There the female character as a romantic partner has significant meaning.
} 
Bethesda Softworks, 2011), for example, the female character is not connected with sexuality, since in effect eroticism rarely surfaces in such games. Here, the female character is equal to the male one - she may be a warrior, a magician, or a thief. The difference is in the physical appearance (outfit emphasizing the figure, breasts, long legs and thighs), yet when it comes to their identity and personal history, regardless of gender, same template applies to the main character. Such templates also include possibilities of navigating the male or female character through romantic endeavors with characters or both sexes (homosexual romances are also feasible). In other words, the female character has no limitations on the plot or her function in the games' world.

This notion is confirmed by current RPG action type video games. It is especially relevant in the infamous Mass Effect or Witcher series. Women are rather particular characters in these games, as in both examples their status is quite high-level. In the Mass Effect series, the woman appears as both a lead and supporting character. The player has the ability to choose the gender of the commander named Shepard and decide to keep him as such or alter him to become Jane Shepard, a female variant. Incidentally, Jane Shepard's character traits are no different than those of her male counterpart's.

Perhaps it is because during the course of the game, it is the player who controls the female protagonist that decides as to her attributes, actions, and conduct. Subsequently, all this is directly linked to specific consequences. Such dilemmas, as the selection of possible courses of action and their potential ramifications, are transferred on the male equivalent of the female commander. Thus, her gender makes no difference. In analyzing female characters in video games, it is unsuitable to take into account Mass Effect's protagonist, since her gender in this case is irrelevant. The issue of her social status, which is one of a liberator of humankind, military commander, and a person responsible for a mission to save all life in the universe, is undoubtedly significant (Jørgensen, 2010). As a protagonist (a prominent person in the story-line), her function in the world of the game is crucial. Female characters are notably more interesting in the whole scope of the game. In contrast to other games, they serve greater roles. They are often physicians, politicians, and base managers, supervisors of research projects, secret agents, biologists, soldiers, commandos, murderers, or even leaders of revolts or crime-worlds. This applies to female characters of humankind as well as those of other races, such as asarians, krogans, or salarians. In the world created by the BioWare studio, even courtesans are influential and play an important role in the parameters of the game. On the other hand, the component of sexuality applies not to attire (though women's outfits are precisely matched to their proportional bodies), but rather to interpersonal relationships that may end in a romance between commander John Shepard and a woman (with one of the female members of the team, thereby one of the members of the player's squad) or a romance between commander Jane Shepard and a woman (or a man). In the game, we may also observe romances among various crew members of less importance; specifically a relationship between a man (Garrus Vakarian) and a woman (Tali).

Regardless of the fact whether the player has the ability to romance with female characters, all the individuals in the game (including women) possess captivating personal histories that are elaborated, interestingly presented and often transformed into quests for the player.

Having said that, in the Witcher series, and especially in its second installment-Witcher 2: Assassins of Kings (CD Project RED, Namco Bandai Games, 2011)—women, (aside from significances mentioned in 


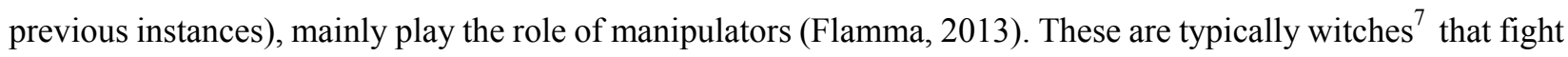
for their primarily political objectives, all the while manipulating the protagonist Geralt; in hopes of achieving a goal, obtaining an artifact, or grabbing Geralt's attention away from some incident. Furthermore, these witches are ruthless, hypocritical, and willing to sacrifice other peoples' lives, just to accomplish their objective. To attain that, they hold numerous possibilities, since as magicians they are customarily respected in society and play a significant part in realm of the game - they are very often kings' advisors, thanks to which they have influence on the turn of political and historical events playing out during the course of the game.

\section{Conclusions}

The "journey" of female characters in video games, from a status of sexual objects to heroines, as presented in this paper, was relatively long and rather complicated. It represents the process of women's emancipation in the realm of video games, as well as freeing from the shackles of stereotypes related to gender and women's sexuality as a whole. It predominantly concerns cRPG, action RPG or adventure-type games. In addition, it is important to keep in mind that even now, erotic video games are being created, in which women (although, in many respects, more and more equal to the male characters) are still depicted as sexual objects. Although, aside from those types of occurrences, women are currently depicted as characters with elaborate personalities, abundant personal histories and having pertinent roles in the world of video games.

However, it is impossible to ignore that women's sexualization in earlier games, was more of a link between the first female character shown in video games (sexual object) and an increased significance of women in story-lines. No doubt it was (and still is) possible to thank to the growth and expansion of female characters; the introduction of new aspects of their characteristics (family situations or psychological problems). It was this growth that became the element, as a result of which female characters could undergo this long journey.

\section{References}

Aarseth, E. (1997). Cybertext: Perspectives on Ergodic literature. Baltimore \& London: John Hopkins University Press.

Anderson M., \& Levene R. (2012). Grand thieves \& Tomb Raiders: How British video games conquered the world. London: Aurum Press Ltd..

Flamma, A. (2013). Virtual relationships. The „Witcher's” video game universe as an example of introducing male-female relationships into virtual world. GV-Proceedings in GV-the 1st Global Virtual Conference, 345-348.

Hatton, E., \& Trautner, M. N. (2011). Equal opportunity objectification? The sexualization of men and women on the cover of „Rolling Stone”. Sexuality \& Culture, 15, 256-278.

Jørgensen, K. (2010). Game characters as narrative devices. A comparative analysis of "Dragon Age: Origins" and "Mass Effect 2". Eludamos. Journal for Computer Game Culture, 4(2), 315-331.

Kennedy, H. W. (2002). Lara Croft: feminist icon or cyberbimbo? On the limits of textual analysis. Game Studies: International Journal of Computer Games Research, 2(2), Retrived from http://www.gamestudies.org/0202/kennedy/

Mcconnell, E. (2011). Top 10 positively portrayed female game characters. Retrieved from $\mathrm{http}$ //listverse.com/2011/05/21/top-10-positively-portrayed-female-game-characters/

Schleiner. A.-M. (2001). Does Lara Croft wear fake polygons? Gender and gender-role subversion in computer adventure games. Leonardo, 34(3), 221-226.

\footnotetext{
${ }^{7}$ Games involving Geralt should be looked at in a particular manner, as they are based on a realm created and presented in Andrzej Sapkowski's prose. Therefore, the way his world functions, as well as his characters' traits, are predominantly a reflection of literary vision.
} 
Scolari, C. A. (2009). Transmedia storytelling: Implicit consumers, narrative worlds, and branding in contemporary media production. International Journal of Communication, 3, 586-606.

Sharkey, S. (2008). Top 5 most attracitive non-sexualized women in video games. Retrieved from http://www.1up.com/features/top-5-attractive-nonsexualized-women 